\title{
LA TRASCENDENCIA CONSTITUCIONAL DEL DEFICIENTE CONTROL DEL DECRETO LEY AUTONÓMICO'
}

\section{The constitutional transcendence of the poor control of the autonomous decree law}

\author{
IGNACIO GONZÁLEZ GARCÍA \\ Universidad de Murcia \\ igongar@um.es
}

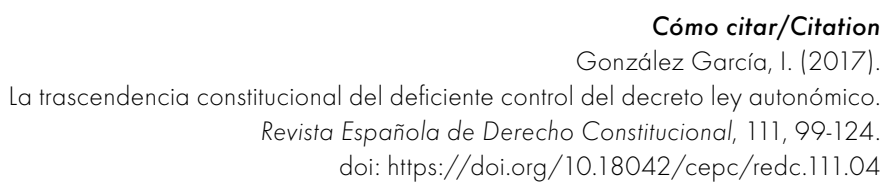

\section{Resumen}

Este trabajo defiende, en principio, la constitucionalidad e incluso la pertinencia de la incorporación de los decretos leyes a los sistemas de fuentes autonómicos. Sin embargo, en él se detalla cómo los estatutos de autonomía no solo han reproducido los importantísimos déficits de control, tanto jurisdiccional como parlamentario, de la correspondiente figura estatal, sino que han profundizado en los mismos, hasta el punto de llevarnos muy cerca de un escenario de dudosa constitucionalidad. Se plantean concretas propuestas de reforma al respecto.

\section{Palabras clave}

Decreto ley; comunidades autónomas; control parlamentario; control jurisdiccional.

1 Trabajo realizado en el marco del proyecto de investigación de la UAM «Las posibilidades del Estado jurisdiccional autonómico: tras la sentencia del Estatut, en la actual situación de crisis económica y bloqueo constitucional» (DER 2012-34428). 


\section{Abstract}

This work defends, initially, the constitutionality as well as the pertinence of the incorporation of the Decree laws to the systems of sources of Autonomous Communities. Notwithstanding, it also explains how the Statutes of Autonomy not only cultivated the severe deficits of control, both jurisdictionally and parliamentary, of the corresponding state system, but also have further deteriorated them to the point of possible dubious constitutionality. Specific proposals for reform are therefore presented.

\section{Keywords}

Decree law; Autonomous Communities; parliamentary control; jurisdictional control. 
I. SOBRE LA CONSTITUCIONALIDAD Y APARENTE IMPERTINENCIA DE LA INCORPORACIÓN DEL DECRETO LEY AL SISTEMA AUTONÓMICO DE FUENTES. II. LA REPRODUCCIÓN DEL MODELO ESTATAL Y DE SU MALA PRAXIS. III. PARTICULARES DÉFICITS DE CONTROL DE LOS DECRETOS LEYES AUTONÓMICOS: 1. Punto de partida. 2. El más difícil acceso a la jurisdicción constitucional. 3. El notable debilitamiento de su control parlamentario. IV. CONSIDERACIONES FINALES. BIBLIOGRAFía.

\section{SOBRE LA CONSTITUCIONALIDAD Y APARENTE IMPERTINENCIA DE LA INCORPORACIÓN DEL DECRETO LEY AL SISTEMA AUTONÓMICO DE FUENTES}

Existe una casi total unanimidad doctrinal acerca de la constitucionalidad de la reciente y paulatina incorporación de la figura del decreto ley al sistema de fuentes de varias de nuestras comunidades autónomas a través de la reforma de los correspondientes estatutos de autonomía ${ }^{2}$. Es ciertamente minoritaria la postura de quienes sostienen la inconstitucionalidad de que los estatutos puedan crear este tipo normativo. Postura que sostienen en un

2 Art. 50.4 Ley Orgánica 1/2006, de 10 de abril, de Reforma de la Ley Orgánica 5/1982, de 1 de julio, de Estatuto de Autonomía de la Comunidad Valenciana; art. 64 Ley Orgánica 6/2006, de 19 de julio, de Reforma de la Ley Orgánica 4/1979, de 18 de diciembre, de Estatuto de Autonomía de Cataluña; art. 49 Ley Orgánica 1/2007, de 28 de febrero, de Reforma de la Ley Orgánica 2/1983, de 25 de febrero, de Estatuto de Autonomía de las Islas Baleares; art. 110 Ley Orgánica 2/2007, de 19 de marzo, de Reforma de la Ley Orgánica 6/1981, de 30 de diciembre, de Estatuto de Autonomía para Andalucía; art. 44 Ley Orgánica 5/2007, de 20 de abril, de Reforma de la Ley Orgánica 8/1982, de 10 de agosto, de Estatuto de Autonomía de Aragón; art. 25.4 Ley Orgánica 14/2007, de 30 de noviembre, de Reforma de la Ley Orgánica 4/1983, de 25 de febrero, de Estatuto de Autonomía de Castilla y León; art. 21 bis Ley Orgánica 7/2010, de 27 de octubre, de Reintegración y Amejoramiento del Régimen Foral de Navarra, de Reforma de la Ley Orgánica 13/1982, de 10 de agosto, de Reintegración y Amejoramiento del Régimen Foral de Navarra; art. 33 Ley Orgánica 1/2011, de 28 de enero, de Reforma de la Ley Orgánica 1/1983, de 25 de febrero, de Estatuto de Autonomía de Extremadura; y art. 30.3 Ley Orgánica 7/2013, de 28 de noviembre, de Reforma de la Ley Orgánica 4/1982, de 9 de junio, del Estatuto de Autonomía para la Región de Murcia. 
presunto paralelismo de nuestro sistema institucional y de fuentes del derecho con el modelo italiano — que no es tal (Tardío Pato, 2013: 321-329)— y en otra serie de argumentos que no hacen a la constitucionalidad de esta cuestión sino a su pertinencia u oportunidad, lo que nos sitúa — como en seguida veremos- en un escenario muy distinto (Boix Papol, 2012: 138-145).

Así pues, vamos a partir en este trabajo de la idea comúnmente aceptada de que los estatutos de autonomía pueden - faltaría más - incorporar al sistema de fuentes de su comunidad autónoma este concreto tipo normativo. $\mathrm{Y}$ ello, en primer lugar, porque la Constitución no lo prohíbe, esto es, no atribuye el monopolio excluyente de la potestad legislativa autonómica a los Parlamentos regionales. Es más, el texto constitucional utiliza $-\mathrm{y}$ no por casualidad- en varias ocasiones giros tan abiertos como «disposiciones normativas con rango de ley de las Comunidades Autónomas» para referirse, genéricamente y en hipótesis, a todas aquellas normas autonómicas que pudieran ostentar dicho rango (arts. 150.3, 161.1.a y 161.2 CE). Y, en segundo lugar, porque los estatutos pueden - y deben - concretar, dentro de los límites constitucionales, su modelo institucional, el correspondiente equilibrio de poderes y el régimen de su sistema normativo ${ }^{3}$.

No cabría, sin embargo, por ese mismo motivo, que las comunidades autónomas dictaran decretos leyes sin habilitación estatutaria previa, ni justificándolo en una aplicación analógica de lo previsto en el art. $86 \mathrm{CE}$ para la figura estatal paralela (no cabría hacer esto respecto de ningún tipo normativo $y$, menos aún, particularmente respecto de esta concreta norma de carácter marcadamente excepcional), ni tampoco bajo el único amparo de una ley autorizante del Parlamento autonómico, que carece en todo caso de tal potestad ${ }^{4}$.

De este modo, una vez aceptada muy mayoritariamente la constitucionalidad de estas previsiones estatutarias, el debate doctrinal se ha ido desplazando hacia su pertinencia, oportunidad o necesidad. Así, los mismos autores que convienen en entender que la incorporación vía Estatuto del decreto ley al sistema de fuentes autonómico no se encuentra viciada de inconstitucionalidad manifiestan claramente que, sin embargo, la creación de este nuevo tipo normativo autonómico resulta innecesaria, cuando no inoportuna e impertinente. Utilizan para justificar su postura argumentos de diversa naturaleza, que se podrían sintetizar de la siguiente manera: a) que durante más de veinticinco años las comunidades autónomas han carecido de este tipo normativo y ello no ha menoscabado el ordinario funcionamiento de sus instituciones

\footnotetext{
3 Véase, en el mismo sentido, por todos, Tur Ausina (1999b: 289-304).

4 Véase, en el mismo sentido, por todos, Donaire Villa (2012: 120).
} 
(De la Iglesia Chamarro, 2013: 2); b) que los Parlamentos autonómicos tienen una carga de iniciativas legislativas mucho menor que el Parlamento estatal (Carmona Contreras, 2006: 20); c) que todos esos Parlamentos autonómicos son unicamerales, lo que acorta los plazos del procedimiento legislativo (Herráiz Serrano, 2011: 107); d) que disponen, además, de procedimientos especiales como las leyes de urgencia, las leyes de comisión y las leyes de lectura única que permiten acelerar la toma de decisiones legislativas (De la Iglesia Chamarro, 2016: 161); e) que el ámbito competencial de las comunidades autónomas no precisa para su eficaz ejercicio un tipo normativo de naturaleza tan urgente y excepcional (Aragón Reyes, 2016: 115).

El primero de tales argumentos resulta claramente insuficiente. El hecho de que hasta ahora las comunidades autónomas no hayan podido disponer de este instrumento normativo y hayan hecho frente a los supuestos de urgencia legislativa de otros modos no hace per se que la incorporación del decreto ley autonómico a los estatutos de autonomía devenga en innecesaria. Recordemos que, en principio, y dada su naturaleza indudablemente excepcional, el decreto ley es un tipo de norma pensada para no ser usada de ordinario. Que la comunidad autónoma la tenga a su disposición por si concurriera el presupuesto extraordinario que habilita su uso, lejos de resultar innecesario, enriquece el sistema autonómico de fuentes. Por otra parte, el último de los argumentos citados, si alguna virtualidad pudo tener en los primeros ańos de desarrollo del Estado autonómico, ha ido decayendo en paralelo al incremento cuantitativo y cualitativo de competencias transferidas a las comunidades autónomas en sus estatutos y sus correspondientes reformas. De hecho, hoy las comunidades autónomas son las Administraciones Públicas que soportan el grueso de las prestaciones propias del Estado social, ámbito donde la incidencia del decreto ley es, en ocasiones, especialmente pertinente (Carmona Contreras, 2013: 4). Finalmente, los argumentos relacionados con la naturaleza, la carga de trabajo y los procedimientos legislativos de los Parlamentos autonómicos también resultan, a mi parecer, fácilmente rebatibles: de un lado, el menor volumen de las tareas legislativas de un Parlamento regional en comparación con el de las Cortes Generales no posibilita en modo alguno que, ante una situación de extraordinaria y urgente necesidad, el Parlamento pueda acortar los plazos que corresponden a cualquier procedimiento legislativo; $y$, de otro lado, la celeridad que aporta al proceso la tramitación de urgencia, por mucho que acortara los plazos de cada una de sus fases, nunca alcanzaría la casi inmediatez de la que dispone el decreto ley. Y me refiero solo al procedimiento legislativo de urgencia, porque los otros dos procedimientos especiales antes referidos — leyes de comisión y leyes en lectura única—, aunque su implementación pueda tener la consecuencia colateral de hacer más breve el lapso 
que precisa el Parlamento regional para adoptar la decisión legislativa que corresponda, el presupuesto que habilita para recurrir a los mismos no es - ni mucho menos - la extraordinaria y urgente necesidad. Cuestión muy distinta y censurable es la habitual mala praxis parlamentaria a la que ya casi nos encontramos acostumbrados. Si, y solo si, junto con la urgencia, concurren además esos otros presupuestos que abren la puerta a la tramitación en lectura única o en comisión, podrán simultanearse ambas especialidades procesales con un resultado final de mayor brevedad en la adopción de la decisión legislativa del Parlamento. Pero, insisto, ni siquiera en tales supuestos se alcanzaría la inmediatez en la respuesta normativa que caracteriza al decreto ley.

Por todo ello, a mi juicio, ninguno de estos motivos, ni la combinación de todos ellos, resulta razón suficiente para afirmar que la incorporación del decreto ley al sistema de fuentes autonómico es innecesaria o, incluso, impertinente. ¿Por qué no dotar a la comunidad autónoma de este excepcional tipo normativo para poder hacer frente a verdaderas situaciones de extraordinaria y urgente necesidad, si las hubiere? Esto no significa, por supuesto, que algunas de estas circunstancias que distinguen la posición de los Parlamentos autonómicos de la posición de las Cortes Generales frente a situaciones de urgencia no deban ser atendidas a la hora de restringir, en la regulación estatutaria y en su interpretación jurisprudencial, el ámbito propio del decreto ley autonómico frente al del decreto ley estatal, como ya puso de manifiesto el Consejo de Garantías Estatutarias catalán en su Dictamen 7/2010, de 22 de abril, sobre el Decreto Ley catalán 2/2010, de 30 de marzo, y, más recientemente, nuestro Tribunal Constitucional en su relevante STC 93/2015, de 14 de marzo, a la que después me volveré a referir. Así, por ejemplo, el carácter unicameral de los Parlamentos autonómicos, junto con la mayor brevedad de los plazos de sus procedimientos legislativos de urgencia y, por tanto, la posibilidad de dar una respuesta normativa más celérica que la de las Cortes Generales habría de limitar más la potestad del Ejecutivo autonómico para apreciar la concurrencia del presupuesto que lo habilita para utilizar este tipo normativo anticipando la reacción del Parlamento.

Lo que sí resulta, sin duda, absolutamente censurable es que los estatutos de autonomía y los correspondientes reglamentos parlamentarios, al configurar este nuevo tipo normativo autonómico, hayan reproducido cuando no agravado - el deficiente régimen jurídico del decreto ley estatal, muy en particular, lo atinente a la regulación de sus controles parlamentario y jurisdiccional. El legislador estatutario se encontraba, tras más de treinta años de uso y abuso de esta figura por parte del Gobierno del Estado, ante la oportunidad de haber dado al decreto ley autonómico una configuración mucho más ajustada a la naturaleza excepcional de este tipo normativo, 
corrigiendo las carencias demostradas y cerrando en lo posible la puerta al abuso de la misma por parte del Ejecutivo. Dicho de otro modo, la incorporación del decreto ley al sistema de fuentes autonómico, per se, ni es inconstitucional, ni habría de considerarse inoportuno o impertinente. Sin embargo, haber trasladado prácticamente in integrum el régimen del decreto ley estatal, con todos y cada uno de sus vicios, sin atender además a las especialidades que en el ámbito autonómico agravan los déficits de control de esta figura, nos sitúa, como detallaremos a continuación, en un escenario en el que incluso se podría llegar a cuestionar la constitucionalidad de la misma.

\section{LA REPRODUCCIÓN DEL MODELO ESTATAL Y DE SU MALA PRAXIS}

Las nueve comunidades autónomas que han incorporado a sus estatutos este tipo normativo lo han hecho recurriendo a diferentes fórmulas, algunas más literalmente ajustadas a la redacción del art. $86 \mathrm{CE}^{5}$ (o incluso remitiéndose al mismo ${ }^{6}$ ) y otras menos mativa de la figura recoge las características esenciales que definen el decreto ley estatal: a) norma con rango de ley aprobada por el Ejecutivo, como excepción a la regla general de monopolio de la potestad legislativa por parte del Parlamento, b) norma de carácter provisional, c) norma sometida a convalidación parlamentaria en un plazo de treinta días, d) posibilidad de modificación del decreto ley por el Parlamento siempre tras su previa convalidación, e) elenco de materias vetadas para este tipo normativo, f) e idéntico presupuesto habilitante, la concurrencia de extraordinaria y urgente necesidad ${ }^{8}$.

5 Por ejemplo, el art. 33 Estatuto de Autonomía de Extremadura.

Art. 50.4 Estatuto de Autonomía de Valencia.

Por ejemplo, el art. 44 Estatuto de Autonomía de Aragón.

8 El artículo 25 del proyecto de la fallida reforma estatutaria de Canarias pudo haber constituido la única excepción a ello. En su texto se proponía un presupuesto habilitante mucho más limitado puesto que se definía expresamente la extraordinaria y urgente necesidad a los siguientes términos: «1. En caso de extraordinaria y urgente necesidad, justificada por circunstancias catastróficas o de emergencia, el Gobierno podrá dictar normas con rango de ley que recibirán el nombre de Decretos-leyes. 2. Igualmente podrá ejercer esta potestad cuando, habiendo enviado al Parlamento un Proyecto de Ley, su objeto pudiera verse gravemente obstaculizado por la aplicación de las normas vigentes o por el ejercicio de los derechos derivados de éstas, mientras se produce la tramitación parlamentaria de aquél [...]». Disponible en: www.parcan. es/leyes/entramite.py. 
Así las cosas, a idéntica configuración normativa, hemos de entender aplicable también al decreto ley autonómico la muy laxa doctrina del Tribunal Constitucional sobre los requisitos formales, materiales y funcionales de la paralela figura estatal, muy en particular lo atinente a la concurrencia del presupuesto habilitante y su motivación. Lógicamente, no corresponde hacer aquí repaso completo de los diferentes contornos de la extensa doctrina del Tribunal Constitucional sobre el decreto ley estatal, pero sí dejar constancia de que el criterio utilizado para decidir cuándo este tribunal debe intervenir en la determinación del presupuesto habilitante, esto es, en qué casos puede entrar a decidir si concurre o no la extraordinaria y urgente necesidad que justifica la aprobación de un decreto ley por el Gobierno del Estado, se ha trasladado en términos absolutamente equivalentes al supuesto de los decretos leyes autonómicos. Es jurisprudencia consolidada del Tribunal Constitucional que la apreciación de la concurrencia de este presupuesto habilitante es un juicio de naturaleza estrictamente política que corresponde al Ejecutivo y que solo se puede corregir en sede de jurisdicción constitucional en casos de arbitrariedad manifiesta9. Y, en esta misma línea, la STC 93/2015, de 14 de mayo, la primera referida a un decreto ley autonómico ${ }^{10}$, pese a admitir claramente que las diferentes condiciones estructurales del parlamentarismo autonómico y las características de sus procedimientos legislativos a las que nos referimos al comienzo de este trabajo (en particular, el carácter unicameral de los parlamentos autonómicos y la especial celeridad de sus procedimientos legislativos de urgencia) son «dentro de la valoración conjunta de factores que implica el control externo del presupuesto que habilita a acudir al Decreto-ley, un elemento de la mayor importancia porque puede hacer posible que las situaciones de necesidad sean atendidas tempestivamente mediante la aprobación de leyes, decayendo así la necesidad de intervención extraordinaria del Ejecutivo» y que, por tanto, tales variables habrán de ser «ponderadas por este Tribunal caso por caso con la vista puesta principalmente en la previsible duración efectiva del procedimiento legislativo y en el grado de inmediatez [requerido] en

9 Una línea jurisprudencial más rigurosa pareció abrir la STC 68/2007, de 28 de marzo, que declaró inconstitucional el Decreto Ley estatal 5/2002, de 24 de mayo, de medidas urgentes para la reforma del sistema de protección por desempleo y mejora de la ocupabilidad, si bien la postura del Tribunal expresada en esa sentencia se fue debilitando en pronunciamientos posteriores, como por ejemplo en la STC 137/2011, de 14 de septiembre, para quedar definitivamente cerrada en la STC 93/2015, de 14 de mayo.

10 Decreto-Ley 6/2013, de 9 de abril, de medidas para asegurar el cumplimiento de la función social de la vivienda (Andalucía). 
la reacción normativa», acto seguido desactiva su propio argumento añadiendo que «no procede, sin embargo, exigir al Gobierno autonómico, para entender realizada la motivación de la situación de necesidad que le incumbe, una justificación expresa e individualizada de la inadecuación del procedimiento legislativo para atender a tiempo los objetivos gubernamentales».

A este respecto, comparto plenamente las recientes críticas de Aragón Reyes (2016: 63-78) a la excesiva laxitud con la que el Tribunal Constitucional ha perfilado la potestad del Gobierno de apreciar la concurrencia del presupuesto habilitante de los decretos leyes y sus demandas de una revisión más rigurosa de esa decisión gubernamental, al menos, en un doble sentido: en primer lugar, que el Tribunal Constitucional exija la justificación expresa de que concurre extraordinaria y urgente necesidad en la exposición de motivos de la norma, so pena de nulidad de la misma, con independencia de que el Tribunal pueda apoyar su juicio sobre este particular en otras fuentes complementarias (por ejemplo, el propio debate parlamentario de convalidación); y que, en todo caso, la labor del Alto Tribunal no se limite a verificar que el Gobierno no ha incurrido en manifiesta arbitrariedad a la hora de apreciar la concurrencia del presupuesto habilitante, sino que aplique sobre esa decisión un juicio de proporcionalidad y adecuación, es decir, que entre a valorar si las medidas adoptadas en el decreto ley para hacer frente a la situación de extraordinaria y urgente necesidad podrían haberse adoptado, sin menoscabo alguno de la eficacia que se pretende dar a las mismas, a través de una decisión legislativa del Parlamento articulada, lógicamente, mediante el procedimiento legislativo de urgencia. Lo que, en mi criterio, no significaría la intervención del Tribunal Constitucional en la decisión política reservada al Gobierno, sino un juicio de revisión estrictamente técnico para el que, por descontado, está constitucionalmente habilitado este órgano. Lamentablemente, la jurisprudencia más reciente de nuestro Tribunal Constitucional, antes citada, no transita todavía por este sendero de mayor rigor sobre la actividad legislativa del Ejecutivo, por lo que esa laxitud en el control se ha trasladado también al ámbito de los decretos leyes autonómicos. Además, en el caso de estos últimos, como señalaremos en el siguiente epígrafe de este trabajo, la debilidad del control jurisdiccional se ve acrecentada notablemente por la muy diferente posición que los Parlamentos autonómicos ocupan frente a las Cortes Generales en los procesos de control de constitucionalidad de las normas con rango de ley autonómicas.

A todo ello hay que añadir que aquellos Ejecutivos autonómicos que, como acabamos de ver, disponen de un instrumento normativo de configuración prácticamente idéntica a la estatal han reproducido también todos y cada uno de los vicios de la práctica estatal. 
Desde el punto de vista cuantitativo, el abuso de la figura es más que notable: durante estos pocos ańos de reconocimiento estatutario del decreto ley autonómico en nueve de las diecisiete comunidades autónomas son ya más de doscientas las normas de esta naturaleza aprobadas (únicamente seis de ellas no convalidadas), sobre un total de tan solo ochocientas leyes autonómicas. La proporción es alarmante y continúa subiendo, como ocurre también en el ámbito estatal, al abrigo de la crisis económica que aún padecemos y que sirve frecuentemente de pretexto a los Ejecutivos para introducir medidas de notable impacto sobre la realidad económica de sus territorios vía decreto ley. $\mathrm{Si}$ bien es cierto que no todas las comunidades autónomas han abusado tanto de esta figura ${ }^{11}$ y que en algunas de ellas —allá donde los Gobiernos han pasado de disfrutar de mayorías absolutas a situaciones de mayoría relativase advierte un tímido crecimiento de la labor de control parlamentario de los decretos leyes ${ }^{12}$, no es menos cierto que las cifras globales de estos últimos años son tan desalentadoras como las estatales ${ }^{13}$.

Desde una óptica cualitativa, el abuso del decreto ley autonómico todavía resulta más preocupante. Como venía ocurriendo ya en el ámbito estatal, se ha utilizado el decreto ley autonómico como reacción singular frente a decisiones judiciales, se han aprobado decretos leyes claramente especiales, otros con contenidos reglamentarios (cuando no auténticamente autoaplicativos), se han utilizado también para trasponer fuera de plazo directivas comunitarias, para dar desarrollo legislativo a disposiciones básicas estatales, y tampoco es infrecuente encontrar decretos leyes ómnibus en prácticamente todos los ordenamientos jurídicos autonómicos donde el Ejecutivo dispone de este

11 Mientras que, por ejemplo, en Andalucía el volumen de decretos leyes aprobados ha llegado a alcanzar el $65 \%$ de la producción legislativa del período 2008-2015, en otras comunidades autónomas como Navarra apenas alcanza el $4 \%$.

12 Sirva como ejemplo que ilustra tal afirmación la situación de la comunidad autónoma de la Región de Murcia: desde la entrada en vigor en 2013 de la reforma estatutaria que permitía al Gobierno regional el uso del decreto ley hasta el final de esa legislatura (mayo de 2015) en que el Ejecutivo dispuso de una amplísima mayoría parlamentaria sobre la que apoyarse (33 de los 45 diputados de la Cámara), todos los decretos leyes dictados por el Gobierno (seis) obtuvieron convalidación parlamentaria; por el contrario, en la actual legislatura, habiendo perdido por un solo escaño la mayoría absoluta, todos los decretos leyes remitidos a la Cámara (cuatro), si bien no han sido derogados, sí han sido sometidos a modificación a través del procedimiento legislativo de urgencia. Véase Instituto de Derecho Público (2013-2016).

13 Véanse datos completos y actualizados relativos a los decretos leyes autonómicos en Aragón Reyes (2016: 116-122) y los relativos a los decretos leyes estatales en Martín Rebollo (2015: 1-117). 
recurso normativo ${ }^{14}$. Y, por último, en lo que respecta a la apreciación de la concurrencia del presupuesto habilitante y su necesaria justificación por parte de los Gobiernos autonómicos, nos encontramos también con una mala praxis evidente: es muy común que en las exposiciones de motivos de estas normas se haga exclusivamente una sucinta alusión a la concurrencia de extraordinaria y urgente necesidad, pero sin concretar en absoluto en qué consiste tal circunstancia para ese supuesto concreto o que, incluso, se prescinda de toda alusión a la misma ${ }^{15}$.

\section{PARTICULARES DÉFICITS DE CONTROL DE LOS DECRETOS LEYES AUTONÓMICOS}

\section{PUNTO DE PARTIDA}

Estamos, por tanto, ante la evidencia de que los estatutos de autonomía han reproducido las carencias y deficiencias del régimen jurídico del decreto ley estatal; de que, además, la extraordinariamente laxa doctrina del Tribunal Constitucional acerca de la potestad del Gobierno para apreciar libremente la concurrencia del presupuesto habilitante también se ha trasladado al caso de los decretos leyes autonómicos y de que, finalmente, los Ejecutivos autonómicos han reproducido la mala praxis abusiva que durante muchos años ha llevado a cabo el órgano de Gobierno estatal.

Nos encontramos, pues, con un problema similar al del Estado: un tipo normativo de naturaleza excepcional cuyos controles - decisivos en su configuración y encaje constitucional - ni se han articulado normativamente ni funcionan en la práctica con el rigor y la eficacia que una figura de estas características requeriría. La situación, además, se agrava cuando se analiza detenidamente el detalle de la regulación autonómica de estos controles, tanto el jurisdiccional como el que puede llevar a cabo el Parlamento autonómico ${ }^{16}$. En efecto, como

14 Véase, al respecto, Arana García (2013: 337-365).

15 Sirvan como respectivo ejemplo de ambas circunstancias los decretos leyes de la Comunidad Autónoma de Murcia 1/2015, de 6 de agosto, de medidas para reducir la carga tributaria en el Impuesto de Sucesiones y Donaciones, y 2/2015, de 6 de agosto, por el que se modifica la Ley 3/2003, de 10 de abril, del Sistema de Servicios Sociales de la Región de Murcia.

16 El Tribunal Constitucional ha venido declarando reiteradamente el carácter compatible y complementario de ambos controles. Valga, por todos, el pronunciamiento recogido en la STC 68/2007, de 28 de marzo: «El interés constitucional de ajustar el 
se señala a continuación, la diferente posición que ocupan los órganos institucionales de las comunidades autónomas en los procesos de control de constitucionalidad, así como el desarrollo que de las previsiones estatutarias han hecho los distintos reglamentos parlamentarios de aquellas autonomías que han recogido este tipo normativo, nos ofrece un escenario de control jurisdiccional y parlamentario del decreto ley autonómico aún más deficiente que el estatal.

\section{EL MÁS DIFÍCIL ACCESO A LA JURISDICCIÓN CONSTITUCIONAL}

Como ya se ha advertido, el Tribunal Constitucional ha optado decididamente por una línea jurisprudencial muy tolerante con la capacidad discrecional de los Ejecutivos — también de los Ejecutivos autonómicos - para apreciar la concurrencia del presupuesto habilitante de los decreto-leyes. Pero más allá de tal circunstancia, en el caso de los decretos leyes autonómicos nos encontramos con un inconveniente añadido: como es bien conocido, las normas con rango de ley de las comunidades autónomas no pueden ser recurridas en inconstitucionalidad por el Gobierno ni por el Parlamento de la propia comunidad autónoma (art. 32.2 LOTC). Se trata de un problema de alcance mucho más general pero que en el particular caso de los decretos leyes autonómicos se torna especialmente grave (Jiménez Asensio, 2001: 92-105). En concreto, resulta de difícil encaje en nuestro modelo de reparto de poderes y en el sistema de fuentes que de él se deriva el hecho de que las minorías de los Parlamentos autonómicos — que, además, como veremos a continuación, tienen muy cercenadas las opciones de control parlamentario sobre el decreto ley- no puedan impugnar ante la jurisdicción constitucional el uso eventualmente abusivo que su Gobierno pueda hacer de un tipo normativo que excepciona la regla general del monopolio de la decisión legislativa autonómica por parte del órgano parlamentario correspondiente. Si censurable es ya la imposibilidad de que estas minorías puedan recurrir la presunta inconstitucionalidad de una decisión de su Parlamento de la que han podido participar con todas las garantías que el

uso del instrumento del Decreto-ley al marco del artículo 86.1 CE no puede considerarse satisfecho por la derivación del Decreto-ley hacia el cauce del artículo 86.3 CE [...]. Pudiera pensarse que una eficacia retroactiva de la ley que diera cobijo a los efectos producidos por el Decreto-ley puede privar de sentido a la impugnación [del] Decreto-ley, [...] esto no es así, pues [...] velar por el recto ejercicio de la potestad de emitir Decretos-leyes, dentro del marco constitucional es algo que no puede eludirse por la utilización del procedimiento del artículo 86.3 CE». Véase un comentario completo a esta sentencia en Díaz de Mera Rodríguez (2011: 146-154). 
sistema exige, más aún lo es cuando aquellas —y el conjunto de los representantes parlamentarios - han quedado excepcionalmente al margen del proceso de elaboración y aprobación de la norma.

Las cifras ilustran de manera más que elocuente esta circunstancia: mientras que los decretos leyes aprobados por el Ejecutivo estatal son prácticamente recurridos de modo sistemático y sin apenas excepciones por las minorías parlamentarias de Congreso y Senado, solo nueve de los más de doscientos decretos leyes autonómicos aprobados hasta la fecha han sido recurridos en inconstitucionalidad, seis de ellos presentados por el presidente del Gobierno estatal, en todos los cuales se alega por el recurrente, curiosa y paradójicamente, falta de concurrencia del presupuesto habilitante. Y de esos nueve procesos de control de constitucionalidad de decretos leyes autonómicos, cinco están todavía pendientes de resolución por el Tribunal Constitucional, por lo que disponemos tan solo de cuatro sentencias sobre el particular ${ }^{17}$. ¿A través de qué vías alternativas al recurso de inconstitucionalidad podrían llegar al Tribunal Constitucional impugnaciones relativas a decretos leyes autonómicos?

En primer lugar, lógicamente, a través de la cuestión de inconstitucionalidad planteada por los jueces y tribunales ordinarios. Esta vía todavía no ha sido muy utilizada (solo una cuestión de inconstitucionalidad planteada frente a un decreto ley autonómico ${ }^{18}$ ), pero además hay que destacar que es un cauce fuertemente limitado por el propio Tribunal Constitucional, el cual viene inadmitiendo un altísimo porcentaje de las cuestiones de inconstitucionalidad planteadas frente a decretos leyes estatales, particularmente cuando el motivo de inconstitucionalidad alegado por el juez es la falta de concurrencia del presupuesto habilitante. El Tribunal inadmite las cuestiones en la inteligencia de

17 STC 93/2015, de 14 de mayo, sobre el Decreto Ley de Andalucía 6/2013, de 9 de abril, de medidas para asegurar el cumplimiento de la función social de la vivienda; STC 107/2015, de 28 de mayo, sobre el Decreto Ley de Cataluńa 5/2012, de 18 de diciembre, del impuesto sobre los depósitos en las entidades de crédito; STC 230/2015, de 5 de noviembre sobre el Decreto Ley de Andalucía 5/2010, de 27 de julio, por el que se aprueban medidas urgentes en materia de reordenación del sector público; y STC 38/2016, de 3 de marzo, sobre el Decreto Ley de las Islas Baleares $5 / 2013$, de 6 de septiembre, por el que se adoptan determinadas medidas urgentes en relación con la implantación, para el curso 2013-2014, del sistema de tratamiento integrado de las lenguas en los centros docentes no universitarios.

18 Cuestión de inconstitucionalidad 6599-2015 interpuesta por la Sala de lo Contencioso-Administrativo del TSJ de Cataluña contra el apartado 3.a del art. 21 del Decreto Ley de Cataluña 1/2009, de 22 de diciembre, de Ordenación de los Equipamientos Comerciales. 
que el motivo impugnatorio se encuentra notoriamente infundado en la cuestión planteada. Siendo ello evidente en algunas ocasiones, en otras no lo es tanto. De hecho, como se ha puesto de manifiesto más de una vez en varios votos particulares de algunos magistrados a esos autos de inadmisión ${ }^{19}$, resulta - cuando menos - cuestionable que se califique como notoriamente infundada una cuestión de inconstitucionalidad que alega falta de concurrencia de la extraordinaria y urgente necesidad requerida en estos casos, que precisa para justificar su inadmisión, a juicio del Tribunal, de extensísimos autos —algunos de más de cuarenta páginas—, de notable densidad y complejidad argumental, acerca de los cuales existe una notable disparidad de criterios dentro de la propia sala como evidencia el hecho de que se acompañen de los correspondientes votos particulares. Parece claro que el Tribunal Constitucional pretende minimizar el acceso al control de constitucionalidad de los decretos leyes por esta vía, al menos de los decretos leyes estatales (Cuberto Truyo, 2015: 1-14). Todavía es pronto para valorar si esta será también la línea a mantener respecto de los decretos leyes autonómicos, pero convendría que el Tribunal valorara las muy dispares condiciones de acceso a su jurisdicción vía recurso de inconstitucionalidad de este tipo de normas autonómicas frente a las estatales de idéntica naturaleza y flexibilizara, por tanto, en estos supuestos, su muy riguroso criterio de inadmisión de cuestiones de inconstitucionalidad.

En segundo lugar, algún autor ha sugerido la posibilidad de plantear recurso de amparo frente a decretos leyes en el muy particular caso de que esta norma, amén de lesionar algún derecho fundamental objeto de protección por esta vía, tuviera la condición de lo que se ha dado en llamar decreto ley autoaplicativo, esto es, que el Gobierno hubiera revestido de ropajes de norma con rango de ley lo que en realidad es un verdadero acto administrativo, impugnable, por tanto, a través del recurso de amparo (Arana García, 2013: 357). Aunque, dadas las circunstancias aquí descritas, es lógico que esta aventurada posibilidad nos genere, sin duda, alguna simpatía, parece claro que tal argumento no resulta en absoluto suficiente como para torcer la literalidad de lo dispuesto en los arts. 41 y 42 LOTC, y menos aún para trocar la reiterada jurisprudencia del propio Tribunal Constitucional a este respecto.

Finalmente, cabría buscar refugio en el conflicto de competencias o, incluso, en el conflicto en defensa de la autonomía local como vías alternativas para hacer llegar al Tribunal Constitucional el enjuiciamiento de un decreto ley autonómico, pero las evidentes limitaciones y condicionantes subjetivos y objetivos de estos recursos los convierten en cauces notoriamente insuficientes.

19 Véase, por ejemplo, ATC 43/2014, de 12 de febrero. 
Y, en cualquier caso, por mucho que pretendiéramos estirar las posibilidades que la cuestión de inconstitucionalidad o, incluso, el recurso de amparo pudieran brindarnos para facilitar el pronunciamiento del Tribunal Constitucional acerca de la validez de los decretos leyes aprobados por los Gobiernos autonómicos, ninguna de estas vías lograría solventar el problema principal, que no es tanto poner a disposición del Tribunal el enjuiciamiento del decreto ley autonómico como que puedan ser las minorías parlamentarias correspondientes quienes puedan articular el recurso.

\section{EL NOTABLE DEBILITAMIENTO DE SU CONTROL PARLAMENTARIO}

Como venimos apuntando, los datos relativos al control por los Parlamentos autonómicos de los decretos leyes resultan absolutamente desalentadores: de los más de doscientos decretos leyes autonómicos dictados durante estos años, tan solo el $3 \%$ de los mismos no se ha convalidado y únicamente el $12 \%$ ha sido sometido a alguna modificación parlamentaria tras su ratificación. Y ello, al margen —claro está- del decisivo papel de la concreta configuración de los equilibrios políticos de cada Cámara, se explica — desde el punto de vista jurídico- en razón de un motivo principal: la regulación de la preceptiva intervención de los Parlamentos sobre el decreto ley dictado por el Gobierno regional recogida en los estatutos de autonomía y en los correspondientes reglamentos parlamentarios no ha introducido prácticamente ninguna mejora o intensificación del control parlamentario que la legislación estatal prevé para los decretos leyes aprobados por el Ejecutivo central, sino que se han reproducido — cuando no agravado - cada una de las carencias de ese modelo.

En el lado de la balanza de las novedades introducidas por la regulación autonómica en orden a reforzar la labor de supervisión parlamentaria de estos tipos normativos, en comparación con lo que ha venido sucediendo respecto de los decretos leyes estatales, podemos destacar tan solo dos:

a) La incorporación, únicamente en la Comunidad Autónoma de Cataluña, de la posibilidad de realizar un juicio previo acerca de la validez del decreto ley autonómico por parte del Consejo de Garantías Estatutarias, a solicitud del Parlamento ${ }^{20}$. En la redacción original del proyecto de reforma del Estatuto de Autonomía catalán de 2006, ese control se llevaba a cabo por el propio Parlamento, que había de

20 Art. 76.2.b Estatuto de Autonomía de Cataluña y arts. 16.1.c y 23.c Ley 2/2009, de 12 de febrero, del Consejo de Garantías Estatutarias. 
decidir por una abultada mayoría de 3/5 del Pleno la concurrencia del presupuesto habilitante de la extraordinaria y urgente necesidad ${ }^{21}$. Ese planteamiento inicial de máximos — probablemente poco compatible con la naturaleza misma del decreto ley - devino, finalmente, en una muy descafeinada intervención rogada, no preceptiva y no vinculante, del Consejo de Garantías Estatutarias. De hecho, el Ejecutivo catalán aprobó el conflictivo Decreto Ley 2/2010, de 30 de marzo, por el que modificó la Ley 11/2007, de 11 de octubre, de la Corporación Catalana de Medios Audiovisuales, pese al contundente juicio en contrario evacuado por el Consejo de Garantías Estatutarias en su Dictamen 7/2010, de 22 de abril.

b) La mejora técnica introducida en seis de los nueve estatutos de autonomía que han recogido la figura del decreto ley al aludir expresamente a la derogación tácita de estas normas si transcurriera el plazo de treinta días sin convalidación parlamentaria ${ }^{22}$. Se fortalece así la posición del Parlamento en este trámite, se dota de mayor seguridad jurídica al régimen de esta intervención y se cierra el debate doctrinal — si es que todavía existía ${ }^{23}$ - en torno a los efectos jurídicos de la pasividad del Parlamento durante el plazo de vigencia provisional del decreto ley.

Por el contrario, son muy numerosas - y muy relevantes — las carencias del modelo de control parlamentario estatal reproducidas o agravadas en la regulación autonómica de esta figura:

a) De entrada, algunas comunidades autónomas se remiten, sin más, expresa o tácitamente, al régimen jurídico de la intervención del Congreso de los Diputados respecto de los decretos leyes estatales. Así, por ejemplo, el art. 50.4 del Estatuto de Autonomía de Valencia remite directamente al propio art. $86 \mathrm{CE}^{24}$ y los Parlamentos de Murcia y Castilla León, cuyos respectivos reglamentos no dedican precepto

21 Véase en www.parlament.cat/web/documentacio/estatut/index.html.

22 Sirva, por todos ellos, el ejemplo del art. 49.2 Estatuto de Autonomía de Baleares: «Los Decretos-leyes quedarán derogados si en el plazo improrrogable de treinta días subsiguientes a su promulgación no son convalidados expresamente por el Parlamento después de un debate y una votación de totalidad».

23 Véase sobre el particular, Carmona Contreras (1997: 244-251).

24 Art. 50.4 Estatuto de Autonomía de Valencia: «Igualmente, el Consell, en casos de extraordinaria y urgente necesidad, podrá dictar disposiciones legislativas provisionales por medio de Decretos-leyes sometidos a debate y votación en Les Corts, atendiendo a 
alguno al trámite de ratificación de los decretos leyes de sus Ejecutivos, aplican subsidiariamente el Reglamento del Congreso de los Diputados en virtud de sendas disposiciones adicionales ${ }^{25}$.

b) A excepción de Valencia y Extremadura ${ }^{26}$, el resto de comunidades autónomas no establecen obligación para el Ejecutivo de remitir al Parlamento el texto del decreto ley aprobado (ni su memoria y antecedentes). Es más, en la mayor parte de tales supuestos, el dies a quo del plazo de treinta días que tiene el Parlamento para pronunciarse no viene ni siquiera referido a la fecha de publicación del decreto ley (como ocurre en el modelo estatal), sino a la fecha de la promulgación del mismo, sin que exista además plazo perentorio entre la fecha de promulgación y de publicación ${ }^{27}$, por lo que, de facto, el Gobierno podría dejar al Parlamento prácticamente sin margen temporal de maniobra.

c) Todos los estatutos de autonomía de estas nueve comunidades autónomas han recurrido al término convalidación ${ }^{28}$ que usa la Constitución

lo que preceptúa el artículo 86 de la Constitución Española para los Decretos-leyes que pueda dictar el Gobierno de España».

Véase, por ejemplo, disposición adicional 5. a Reglamento de las Cortes de Castilla y León.

26 Art. 137.1 Reglamento de las Cortes Valencianas: "Cuando el Consell, en casos de extraordinaria y urgente necesidad dictare resoluciones legislativas provisionales mediante Decretos-leyes, éstos requerirán la convalidación del Pleno de la Cámara y, por tanto, deberá dar traslado inmediato a la Mesa de las Cortes para su tramitación». Art. 192 Reglamento de la Asamblea de Extremadura: «[...] los Decretos-leyes, una vez aprobados por el Consejo de Gobierno, se enviarán a la Asamblea o Parlamento de Extremadura para la publicación en su Boletín Oficial, con el fin de que en el plazo improrrogable de un mes sean convalidados, en su caso, tras su debate y votación de totalidad [...]".

27 Por todos, art. 161.1 Reglamento del Parlamento de Navarra: «El debate y votación sobre la convalidación o derogación de un Decreto-ley foral se realizará en el Pleno de la Cámara o, en su caso, en la Comisión Permanente, antes de transcurridos los treinta días siguientes a su promulgación, de conformidad con lo establecido en el artículo 21.bis de la Ley Orgánica de Reintegración y Amejoramiento del Régimen Foral de Navarra. En todo caso, la inserción en el orden del día de un Decreto-ley foral para su debate y votación podrá hacerse tan pronto como hubiere sido objeto de publicación en el Boletín Oficial de Navarra».

28 Alguno de ellos al equivalente término validación, por ejemplo el art. 64.2 Estatuto de Autonomía de Cataluña: «Los Decretos-leyes quedarán derogados si en el plazo improrrogable de treinta días subsiguientes a la promulgación no son validados expresamente por el Parlamento [...]». 
para referirse al placet parlamentario del decreto ley, sin atender al criterio jurisprudencial y al amplio acuerdo doctrinal existente en torno a la ausencia de efecto sanador alguno de los eventuales vicios de inconstitucionalidad de los que pudiera adolecer el decreto ley —incluidos aquellos que puede y debe verificar la Cámara - al producirse la ratificación parlamentaria de la decisión gubernamental, lo que habría de llevar al legislador a utilizar cualquier otro término distinto que no evoque erróneamente esa idea de novación sanadora del tipo normativo. Asimismo, todos los estatutos de autonomía utilizan también el término estatal derogación para referirse al efecto de la no convalidación parlamentaria, sin precisar en absoluto el alcance ultraactivo o retroactivo de la misma, lo que deja inconvenientemente abierta una problemática especialmente relevante en estos casos: la proyección temporal del veto parlamentario ${ }^{29}$.

d) Asimismo, todos los reglamentos parlamentarios de las comunidades autónomas que han incorporado este tipo normativo han configurado el trámite de convalidación-derogación del decreto ley autonómico como un debate de totalidad sin posibilidad de introducir enmiendas y con dos breves turnos de intervención por grupo parlamentario, lo que constituye un procedimiento claramente insuficiente de control del decreto ley y, en particular, de la inexcusable participación de las minorías parlamentarias ${ }^{30}$.

e) El Reglamento de alguna comunidad autónoma exige, para tomar la decisión de someter el decreto ley al trámite legislativo de urgencia para su eventual modificación, una decisión del Pleno no ya por mayoría simple (como sucede en el caso de las Cortes Generales), sino

29 Véase, por ejemplo, el art. 110.2 Estatuto de Autonomía de Andalucía: «Los Decretos-leyes quedarán derogados si en el plazo improrrogable de treinta días subsiguientes a su promulgación no son convalidados expresamente por el Parlamento tras un debate y votación de totalidad [...]».

30 Véase, por ejemplo, la Resolución de la Presidencia del Parlamento de Andalucía, de 4 de junio de 2008, sobre control por el Parlamento de los Decretos-leyes dictados por el Consejo de Gobierno: «Primero. El debate y votación sobre la convalidación de un Decreto-ley se realizará en el Pleno o en la Diputación Permanente en el plazo improrrogable de los treinta días siguientes a su promulgación. Segundo. En ambos supuestos, un miembro del Consejo de Gobierno expondrá ante la Cámara las razones que han obligado a la promulgación del Decreto-ley en un debate de totalidad, en el que, tras la exposición del Consejo de Gobierno, intervendrán los Grupos Parlamentarios de menor a mayor. Tercero. Concluido el debate, se procederá a la votación. Si la convalidación no se produjera, el Decreto-ley quedará derogado». 
por mayoría absoluta de la Cámara autonómica ${ }^{31}$, lo que ahonda notablemente esa lesión del derecho de las minorías parlamentarias a ejercer mínimamente una labor de control sobre este tipo normativo gubernamental con rango de ley ${ }^{32}$.

f) Además, en cinco de las nueve comunidades autónomas citadas el reglamento parlamentario permite a la Diputación Permanente de la Cámara no solo decidir la convalidación, derogación o iniciación del trámite legislativo de urgencia para la modificación del decreto ley (como sucede en el caso estatal ${ }^{33}$ ), sino incluso elaborar y aprobar esa ley del Parlamento que vendría a modificar y sustituir al decreto ley autonómico $^{34}$, lo cual, pese al carácter monocameral de los Parlamentos autonómicos, resulta muy cuestionable desde varios puntos de vista y, en particular, desde la óptica de intentar favorecer en lo posible el control parlamentario de estas normas.

g) Y, al margen de todo lo anterior, sin duda la decisión del legislador autonómico que más debilita la posición supervisora del Parlamento sobre esta actividad normativa por parte del Ejecutivo es haber reproducido y consolidado claramente el carácter sucesivo y no alternativo de las tres posibles intervenciones parlamentarias en la fase de control

31 Art. 192 Reglamento Asamblea Extremadura: «[...] A petición de un Grupo Parlamentario, y mediante acuerdo por mayoría absoluta del Pleno, se tramitarán los Decretos-leyes como proyectos de ley por el procedimiento de urgencia, en el plazo establecido en el apartado anterior».

32 Sobre la intervención del Parlamento entendida como cauce para recuperar los derechos de las minorías parlamentarias, véase Carmona Contreras (1997: 232-238) y Tur Ausina (1999a: 91-117).

33 Pese a que el art. 151.5 RCD establece que «la Diputación Permanente podrá, en su caso, tramitar como proyectos de ley por el procedimiento de urgencia los Decretos-leyes que el Gobierno dicte durante los períodos entre Legislaturas», la correcta interpretación constitucional del mismo, atendiendo particularmente a lo previsto en el art. $78 \mathrm{CE}$, es la de entender que lo más que podría hacer la Diputación Permanente del Congreso de los Diputados es adoptar el acuerdo de tramitación del decreto ley como proyecto de ley, pero no desarrollar esa tarea legislativa, circunstancia que además nunca se ha dado en la práctica. Incluso podría discutirse la constitucionalidad de esa ya limitada potestad de la Diputación Permanente en virtud del principio de autonomía de las nuevas Cámaras surgidas del proceso electoral durante cuyo desarrollo actuó la Diputación Permanente. Véase, sobre el particular, Santaolaya Machetti (1988: 182-186) y Jiménez Campo (1982: 35-55).

34 Véase, por todos, el art. 4 de la Resolución de la Presidencia de las Cortes de Aragón, de 14 de diciembre de 2007, sobre el control de los Decretos-leyes. 
(convalidación/derogación/modificación del decreto ley). En efecto, en el modelo estatal, pese a que la Constitución abre la puerta a la alternatividad de estas tres decisiones al establecer que durante el plazo de treinta días las Cortes Generales, además de convalidarlo o derogar el decreto ley, pudieran alternativamente tomar la decisión de «tramitarlo como proyecto de ley por el procedimiento de urgencia» (art. 86.3 CE), el Reglamento del Congreso de los Diputados ha optado por configurar como sucesivas la convalidación del decreto ley y su eventual tramitación por el procedimiento legislativo de urgencia para modificarlo (art. 151.4 RCD) ${ }^{35}$. Esto es, las Cortes Generales pueden optar, lógicamente, por derogar o convalidar el decreto ley, pero si pretenden modificarlo han de convalidarlo previamente. Su modificación no se contempla como una verdadera alternativa a las otras dos decisiones. Pese a las importantes críticas que ha recibido esta previsión del Reglamento del Congreso por parte de un nutrido sector doctrinal ${ }^{36}$, nuestro Tribunal Constitucional avaló desde fecha muy temprana la constitucionalidad de esta previsión reglamentaria en su STC 29/1982, de 31 de mayo, si bien es pertinente destacar ya aquí — por lo que después diremos- que en esa misma sentencia el Alto Tribunal entiende igualmente compatible con el texto constitucional una eventual redacción diferente del Reglamento del Congreso que estableciera el carácter alternativo y no sucesivo de ambas intervenciones parlamentarias:

La doble vía que a estos efectos fiscalizadores prevé el artículo 86 de la Constitución, en sus apartados segundo y tercero ha venido a decantarse en la práctica parlamentaria en el sentido del necesario pronunciamiento sobre la totalidad del Decreto-ley pero una vez convalidado éste, se posibilite el acudir a tramitarlo como proyecto de ley por el procedimiento de urgencia (artículo 86, número 3, de la C.E.), si bien es cierto que nada se opone a una interpretación alternativa de ambas vías, quedando este punto al criterio de oportunidad que puede establecer en un futuro el Congreso de los Diputados.

Pues bien, esta regulación se ha reproducido, exactamente en los mismos términos, en el ámbito autonómico. Los estatutos de autonomía se refieren a

35 Art. 151.4 RCD: "Convalidado un Real Decreto-ley, el Presidente preguntará si algún Grupo Parlamentario desea que se tramite como proyecto de ley. En caso afirmativo, la solicitud será sometida a decisión de la Cámara [...]». La cursiva es mía. 36 Véase, por todos, Carmona Contreras (2013: 17-18) y Tur Ausina (2002: 139-141). 
estas tres decisiones de las Cámaras regionales de un modo tal que se deja la puerta abierta a entenderlas como opciones alternativas: bien convalidar, bien derogar, bien modificar. Sin embargo, todos los reglamentos parlamentarios han optado por configurar convalidación y modificación como trámites sucesivos, estableciendo como necesario el primero para poder poner en marcha el segundo. Sirvan como ejemplo los preceptos correspondientes del Estatuto de Autonomía y del Reglamento Parlamentario de la Comunidad Autónoma de las Islas Baleares: art. 49.2 EAB: «[...] Durante el plazo establecido en el párrafo anterior, el Parlamento podrá acordar la tramitación de los Decretos-leyes como proyectos de ley por el procedimiento de urgencia», y art. 148.4 RPB: "Convalidado el Decreto-ley el Presidente del Parlamento preguntará si algún Grupo Parlamentario desea que se tramite como proyecto de ley. En caso afirmativo, la solicitud será sometida inmediatamente a la decisión de la Cámara [...] $w^{37}$.

Durante todos estos años de uso y abuso del decreto ley por parte del Ejecutivo estatal han sido muchas y muy autorizadas, como se ha señalado, las voces que han censurado duramente que el RCD cerrara la puerta a la alternatividad de estas decisiones parlamentarias por cuanto suponen una merma evidente de las ya menguadas posibilidades de que el Parlamento realice un control eficaz del decreto ley, postura que, lógicamente, compartimos, y no solo por el hecho de que la alternatividad favorezca el control parlamentario, sino porque de este modo se mantiene más claramente el carácter de norma provisional que tiene el decreto ley, con todas las consecuencias que de ello se derivan, particularmente aquellas relacionadas con el alcance y los efectos que la ley de Parlamento que modifica el decreto ley gubernamental pudiera tener.

Lógicamente, el principal de los motivos que lleva al RCD a configurar como necesaria la previa convalidación del decreto ley antes de iniciar su tramitación legislativa por el procedimiento de urgencia es el de prorrogar la vigencia de la norma más allá de los treinta días constitucionalmente previstos, dando tiempo así a que las Cortes Generales puedan concluir el procedimiento que da lugar a la modificación del texto sin que este haya perdido vigencia durante ese lapso temporal, circunstancia que, en efecto, es conveniente atender teniendo en cuenta la naturaleza de los supuestos fácticos que hacen precisa la aprobación por el Gobierno de este tipo normativo. Pero sucede que, una vez situados en el escenario del decreto ley autonómico, este objetivo del legislador estatal pierde o puede perder casi por completo su sentido original: el carácter monocameral de los Parlamentos autonómicos, así como la mayor brevedad de los plazos previstos en sus respectivos procedimientos legislativos de urgencia, harían posible casi en todos los casos una

37 La cursiva es mía. 
alternatividad real y completa para las tres decisiones que puede adoptar la Cámara autonómica. Dicho de otro modo, en el plazo estatutario de treinta días, daría tiempo a tomar la decisión de derogar el decreto ley, convalidarlo o modificarlo sometiéndolo al trámite legislativo de urgencia, esto es, no solo a tomar la decisión de iniciar el proceso legislativo sino a iniciarlo y concluirlo dentro de los treinta días.

Como ya se ha dicho, el Tribunal Constitucional ha admitido el carácter sucesivo de convalidación y modificación del decreto ley estatal como una de las decisiones del Reglamento del Congreso de los Diputados que caben dentro de las posibilidades abiertas por el artículo 86.3 CE, lo cual resulta trasladable a la relación Estatuto de Autonomía-Reglamento Parlamentario autonómico, pero una solución como la aquí descrita se ajustaría mejor, en mi criterio, a la literalidad y finalidad perseguida tanto por el constituyente como por el legislador estatutario, y más aún, teniendo en cuenta estas notables condiciones diferenciales que se dan en los Parlamentos autonómicos.

En esta misma línea de intentar fortalecer la labor de control que el Parlamento estatal realiza sobre los decretos leyes y, en particular, en el ánimo de soslayar las limitaciones que para esa función supervisora introduce el art. 151.4 RCD, configurando como sucesivas las intervenciones de las Cortes Generales, muy recientemente el profesor Aragón Reyes (2016: 170-176) ha propuesto la modificación del citado precepto reglamentario en los siguientes términos: a) mantener el carácter sucesivo de las mismas, pero establecer como obligatorio y no como optativo para el Congreso de los Diputados el inicio de la tramitación del decreto ley por el procedimiento legislativo de urgencia, salvo para los supuestos que la Mesa de la Cámara calificara como estrictamente coyunturales; b) no se afectaría con ello, según este autor, el carácter provisional del decreto ley, aun habiendo sido ya ratificado por el Congreso antes de iniciar su tramitación legislativa completa, pues habría que entender que corresponde a ambas Cámaras determinar el cese de la provisionalidad del decreto ley precisamente a través de este trámite legislativo; y c) la reforma del art. 151.4 RCD en el sentido aquí citado encontraría su apoyatura constitucional en una interpretación del art. 86.3 CE diferente a la hasta ahora aceptada por el Tribunal Constitucional: habríamos de entender que la afirmación en él contenida de que «durante el plazo establecido en el apartado anterior las Cortes podrán tramitarlos [los decretos leyes], como proyectos de ley por el procedimiento de urgencia» habilita al Parlamento estatal para tomar esa decisión caso por caso, como viene haciendo, y también para tomarla con carácter general y previo estableciendo en su reglamento la obligatoriedad de ese trámite para los decretos leyes de una determinada condición, los de naturaleza no coyuntural. 
Pese a las justificables objeciones técnicas y de fondo que pudieran oponerse a esta propuesta de reforma del art. 151.4 RCD, en las que ahora no podemos entrar, compartimos con el profesor Aragón la idea de que la misma contribuiría notabilísimamente a fortalecer la posición de control que el Parlamento siempre debió ejercer sobre la actividad normativa del Gobierno a través de este instrumento. No obstante ello, esta solución, que quizá sí pudiera articularse para los decretos leyes estatales tal y como reivindica este autor, no es trasladable al caso de los decretos leyes autonómicos por los motivos que pasamos a detallar.

Tan solo tres - Cataluña, Extremadura y Valencia- de las nueve Comunidades Autónomas que han recogido este tipo normativo reproducen en su Estatuto de Autonomía una formulación paralela a la del artículo 86.3 CE — «el Parlamento] podrá tramitarlos» ${ }^{38}$ —, que podría abrir la puerta a esa nueva interpretación de la habilitación constitucional —estatutaria, en estos casos- a la Cámara consistente en entender que esa decisión parlamentaria puede adoptar carácter general y previo quedando establecida en el correspondiente reglamento parlamentario. Sin embargo, los otros seis estatutos de autonomía establecen clarísimamente - con dos formulaciones distintas, a cual más rotunda- que esa decisión del Parlamento autonómico de iniciar la tramitación del decreto ley como proyecto de ley del Gobierno por el procedimiento legislativo de urgencia ha de adoptarse necesariamente caso por caso y en el plazo de los treinta días previstos. Así, los estatutos de Castilla León, Andalucía, Navarra y Baleares, establecen que la respectiva Cámara «podrá acordar en el plazo arriba señalado tramitar los Decretos-leyes como Proyectos de Ley por el procedimiento legislativo de urgencia», y los estatutos de Aragón y Murcia, ahondando aún más en esta misma idea, disponen que el Parlamento de esas Comunidades Autónomas "puede tramitar los Decretos-leyes como Proyectos de Ley adoptando el acuerdo correspondiente dentro del plazo establecido en el apartado anterior ${ }^{39}$. Queda claro, pues, que la ambigüedad que un muy importante sector doctrinal quiere ver en la literalidad del art. 86.3 CE no se reproduce en la mayor parte de los estatutos de autonomía cuando establecen el precepto paralelo correspondiente. De este modo, la configuración normativa del control parlamentario de los decretos leyes autonómicos cierra la puerta al intento de mejorar la posición del Parlamento en este trámite por aquella vía.

Por todo ello, se puede - y creemos que se debe - concluir que la solución más eficaz y, además, la más ajustada a la correcta interpretación sistemática de

38 Arts. 64.3 EAC, 33.4 EAE y 50.4 EAV.

39 Véanse, por un lado, los arts. 25.4 EACyL, 110.2 EAAnd, 21.bis.2 LORAFNA y 49.2 EAB; y, por otro, los arts. 44.3 EAAr y 30.3 EAMu. La cursiva es mía. 
la Constitución y los estatutos de autonomía para incrementar el control parlamentario de los decretos leyes autonómicos pasa necesariamente por una reforma de los reglamentos de las Cámaras territoriales que establezca, con todas sus consecuencias, el carácter alternativo de la decisión de ratificar el decreto ley aprobado por el Gobierno o modificar su contenido transformándolo en una ley del Parlamento, iniciando y concluyendo el procedimiento legislativo correspondiente dentro del plazo estatutariamente previsto para su eventual ratificación. Extremo este que - como ya indicamos anteriormenteentendemos, además, perfectamente compatible con la doctrina del Tribunal Constitucional en esta materia.

\section{CONSIDERACIONES FINALES}

La incorporación del decreto ley al sistema de fuentes autonómico a través de su reconocimiento y configuración estatutaria no es per se contrario a lo dispuesto por nuestra Constitución, ni tiene por qué resultar innecesario, inoportuno o impertinente, como se ha venido calificando hasta ahora por la doctrina. Es más que razonable que, llegados al punto en el que se encuentra la distribución territorial de potestades legislativas, las comunidades autónomas puedan disponer de un instrumento normativo de esta naturaleza para poder hacer frente a situaciones de extraordinaria y urgente necesidad. Cuestión muy diferente es que esa configuración estatutaria y reglamentaria del decreto ley autonómico haya reproducido y acrecentado los notables déficits de control jurisdiccional y parlamentario de la paralela figura estatal, y que se haya hecho hasta el punto de vaciar casi completamente las posibilidades reales de fiscalización del decreto ley autonómico por parte del Tribunal Constitucional y de los correspondientes Parlamentos territoriales, lo que, teniendo siempre muy presente la naturaleza excepcional y provisional de este tipo normativo, nos podría llegar a situar muy cerca de un escenario no solo de impertinencia o inoportunidad, sino de dudosa constitucionalidad.

Es, por tanto, preciso que, por un lado, se refuerce el papel que debe jugar la institución parlamentaria en el control de los decretos leyes aprobados por los Ejecutivos autonómicos, en los términos aquí defendidos; y que, por otro, se facilite el acceso de las minorías parlamentarias a la jurisdicción constitucional cuando entiendan que el contenido del decreto ley o las circunstancias de su control parlamentario han vulnerado las irrenunciables garantías constitucionales. Asimismo, entendemos inaplazable la revisión por parte del Tribunal Constitucional de su propia doctrina entorno a las condiciones de la concurrencia y la motivación gubernativa del presupuesto habilitante de este 
tipo normativo. Sin embargo, aunque todo ello revisáramos con éxito, nos encontramos aquí con otro elemento igual de decisivo: el imprescindible autocontrol de los Gobiernos autonómicos a la hora de interpretar y desarrollar los poderes que el bloque de la constitucionalidad les otorga, de todos ellos, pero muy en particular de este concreto instrumento de naturaleza claramente excepcional. Como vemos cotidianamente, para profundo pesar de quienes entendemos la Constitución como un instrumento de limitación del poder público, fiarlo todo al heterocontrol de las instituciones no solo resulta frecuentemente ineficaz, sino que acaba horadando los cimientos del sistema ${ }^{40}$. Sin un mínimo de autocontención por parte de aquellos sujetos que ejercen potestades públicas, cuya condición es per se limitada en todo Estado constitucional, ningún control externo podrá resultar nunca plenamente efectivo. Y el decreto ley autonómico no es una excepción.

\section{Bibliografía}

Aragón Reyes, M. (2016). Uso y abuso del Decreto-ley: una propuesta de reinterpretación constitucional. Madrid: RALJ-Iustel.

Arana García, E. (2013). Uso y abuso del Decreto-ley. Revista de Administración Pública, 191, 337-365.

Boix Palop, A. (2012). La inconstitucionalidad del Decreto-ley autonómico. Asamblea: Revista de la Asamblea de Madrid, 27, 121-148.

Carmona Contreras, A. M. (1997). La configuración constitucional del Decreto-ley. Madrid: CEPC.

- (2006). La incorporación de la potestad gubernamental de urgencia a los nuevos Estatutos de Autonomía: consideraciones críticas. Revista Vasca de Administración Pública, 76, 15-38.

- (2013). El Decreto-ley en tiempos de crisis. Revista Catalana de Dret Public, 47, 1-20.

Cubero Truyo, A. (2015). La posición del Tribunal Constitucional sobre el Decreto-ley, a través de sus autos de inadmisión a trámite de las cuestiones de inconstitucionalidad. Revista Aranzadi Doctrinal, 7, 1-14.

40 Compartimos en este punto la reflexión que, con alcance más general, hace Jiménez Asensio (2016: 258-259) cuando afirma que «habrá pocos países en el mundo que dispongan de una estructura institucional tan prolija en mecanismos de supervisión y control del poder [como el nuestro] [...]. Sin embargo, a nadie mínimamente informado se le escapa que todo este alambicado panorama institucional no funciona. Está basado en la trampa de las apariencias [...]. Pero no es tanto un problema de diseńo como de funcionamiento o rendimiento institucional, al fin y a la postre de cultura político-constitucional». 
De la Iglesia Chamarro, A. (2013). Los Decretos-leyes autonómicos en España: una aproximación crítica. Osservatorio sulle Fonti. Rivista di Diritto Costituzionale, 1/2013, 1-26.

- (2016). El Decreto-ley autonómico: ¿una fuente más o nuevo problema constitucional? En VV. AA. La Constitución Politica de España: estudios en homenaje a Manuel Aragón Reyes (pp. 161-178). Madrid: CEPC.

Díaz de Mera Rodríguez, A. (2011). Gobierno en crisis. Uso y abuso del Decreto-ley. Asamblea: Revista Parlamentaria de la Asamblea de Madrid, 24, 137-178.

Donaire Villa, F. J. (2012). Las normas con fuerza de ley de las Comunidades Autónomas. Las figuras del Decreto Legislativo y del Decreto-ley autonómicos. Barcelona: IEA.

Herráiz Serrano, O. (2011). Teoría y práctica del Decreto-ley autonómico tras su incorporación al sistema de fuentes de algunas Comunidades. Corts: Anuario de Derecho Parlamentario, 25, 105-161.

Instituto de Derecho Público. (2013-2016). Informe de Comunidades Autónomas. Barcelona: IDP.

Jiménez Asensio, R. (2001). La ley autonómica en el sistema constitucional de fuentes del Derecho. Madrid: Marcial Pons.

- (2016). Los frenos del poder. Separación de poderes y control de las instituciones. Madrid: IVAP-Marcial Pons.

Jiménez Campo, J. (1982). Las Diputaciones Permanentes y el control sobre el Decreto-ley. Revista de Derecho Político, 15, 35-55.

Martín Rebollo, L. (2015). Uso y abuso del Decreto-ley. Un análisis empírico. Revista Española de Derecho Administrativo, 174, 1-117.

Santolaya Machetti, P. (1988). El régimen constitucional de los Decretos-leyes. Madrid: Tecnos.

Tardío Pato, J. A. (2013). La introducción de Decretos-leyes autonómicos en España. Revista Española de Derecho Administrativo, 160, 319-359.

Tur Ausina, R. (1999a). La participación de la oposición en el control de los Decretos-leyes. Cuadernos de Derecho Público, 8, 91-117.

- (1999b). A propósito de los Decretos-leyes autonómicos: perspectivas y posibilidades. Corts: Anuario de Derecho Parlamentario, 7, 289-306.

- (2002). El control parlamentario de los Decretos-leyes. Madrid: CEPC. 